\title{
THE VALUE OF KNOWLEDGE THROUGH H-BIM MODELS: HISTORIC DOCUMENTATION WITH A SEMANTIC APPROACH
}

\author{
P. Parisi *, M. Lo Turco *, E. C. Giovannini * \\ ${ }^{*}$ DAD, Department of Architecture and Design, Politecnico di Torino, Italy \\ pgiorgio.parisi@gmail.com, (massimiliano.loturco, elisabettacaterina.giovannini)@polito.it
}

\section{Commission II}

KEY WORDS: 3D Modelling, Data Modeling, HBIM, Paradata Documentation, CIDOC-CRM

\begin{abstract}
:
The Building Information Modeling (BIM) in the Architectural Heritage field is constantly proving to be a fertile ground for the experimentation of innovative systems for the enhancement and management of cultural heritage. Regarding to the management of the entire process, the building field is increasing in efficiency from the construction to the management phase; conversely, the approach to historical buildings opens up interesting and heterogeneous scenarios, according to different levels of complexity. The presented work is the result of a collaboration between the Politecnico di Torino and the Escuela Técnica Superior de Arquitectura of Granada: the main scope was to create an historic building information model (H-BIM) of the building that today hosts the Faculty of Architecture (ETSAG), taking into account its historical past from the sixteenth century up to the present day, as the result of many modifications, extensions and different use classifications over time. According to this, the BIM methodology can be considered as a bridge between the archive documentation and the digital model, proving to be an effective tool as a data repository, semantically oriented, not only constituted by geometry, but also by alpha-numerical attributes, improving in effectiveness if it is directly related to formal language object oriented.
\end{abstract}

\section{INTRODUCTION}

The research activity is part of an international research framework on the capabilities of extending principles and criteria of semantic modelling of information in Cultural Heritage: the aim is a critical evaluation of the BIM methodology as a possible platform for the representation and the sharing of information for historical architecture, precisely working on the data collection and classification that can be associated to the parametric model. In order to give evidence of the documents collected during the survey phase, it is necessary to set up a shared and interoperable work environment, able to store and provide graphic and alphanumeric information through a direct association between the BIM environment and the formalization of ontologies.

\section{BACKGROUND}

The innovation of digital tools to support new methodologies is a fertile ground for experimentation and application work, providing increasingly reliable operational strategies to manage the entire process in a BIM environment: these processes are now supported by a regulation dedicated to these issues, oriented towards an increasingly marked adoption of computerized processes.

Research and national/international regulatory laws are in constant relationship, in order to outline common guidelines and standards. In this regard, Italy is making a considerable contribution, bringing to the CEN (European Committee for Standardization) the outcomes of what has been developed by the Ente Nazionale Italiano di Unificazione (UNI): the law

\footnotetext{
* Although the contribution was conceived jointly, Piergiorgio Parisi is author of paragraphs 3 and 4.1; Massimiliano lo Turco of paragraphs 1, 2, 4, 4.2 and 5; Elisabetta C. Giovannini of paragraph 4.3
}

"UNI 11337: Building and civil engineering works - Digital management of construction information processes" constitutes an important reference point in this field, introducing new concepts on the Levels of Developments (LOD), and opening a discussion on the use of this methodology also applied to architectural heritage and restoration ("UNI 11337," 2017). It is well established that the most recent digital methodologies have reached full maturity in the context of new building interventions. As far as the interventions on the built environment are concerned, with particular reference to the BIM methodology for Cultural Heritage, there are still very few research experiences aimed at understanding the potential in the specific field of historical architectures. Actually this is a cutting-edge research theme: the first issue concerns the lack of components/tools for the modelling of historical architecture within commercial platforms.

In this respect, the reconstruction of complex and nonstandardized forms still seems to be a particularly onerous activity. In the literature, some interesting works illustrate possible approaches that adopt different applications for converting point clouds into intelligent parametric objects, introducing the concept of Level of Accuracy (Santagati \& Lo Turco, 2016), often oriented towards the purely metrical aspects. In other researches the rigorous approach to BIM is revealed in the evaluation of the Level of Reliability of the information (Nicastro, 2015).

With regard to the structuring of ontologies in the field of cultural heritage, there are interesting researches that aim to go beyond the simple construction of a database, working with tools that support the process of cultural heritage conservation (Doerr, Ore, \& Stead, 2007). According to the methodological 


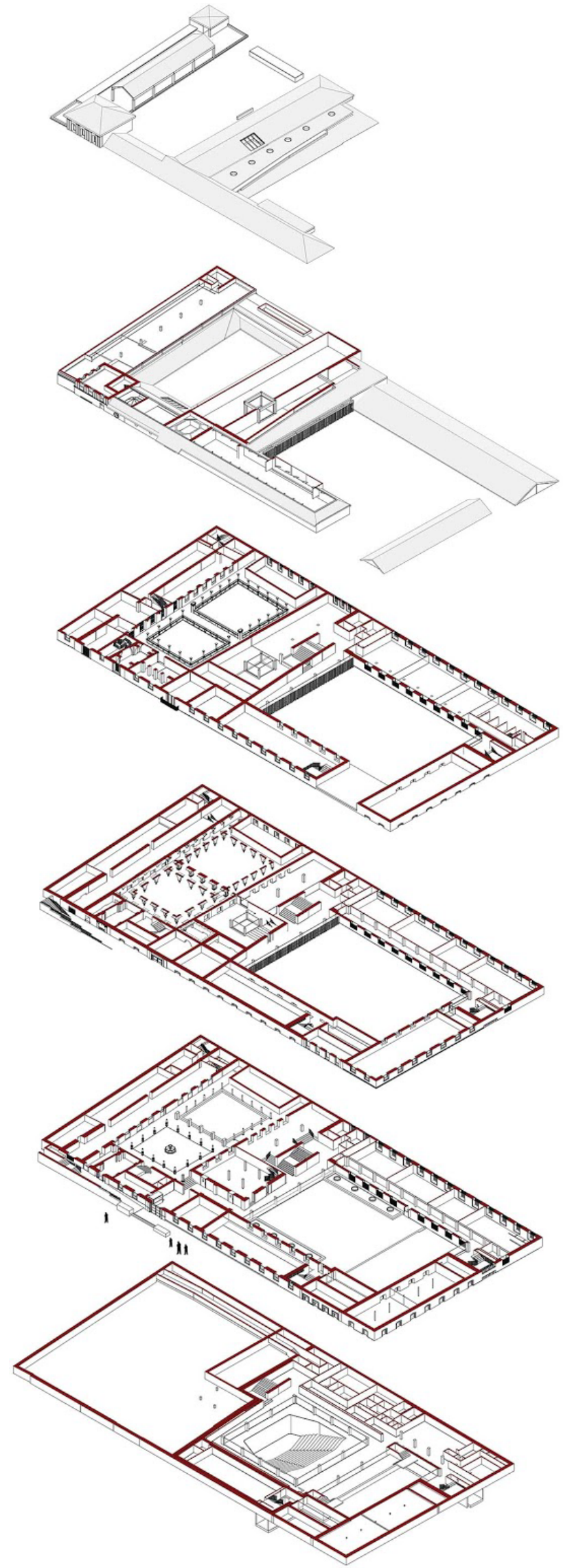

Figure 1. Axonometric cross-section of the building complex of the Escuela Técnica Superior de Arquitectura in Granada. definition of the formalization of a conceptualization (Gruber, 2009) there are some research experiences that define computer ontologies in the field of cultural heritage (Felicetti, Scarselli, Mancinelli, \& Niccolucci, 2013)(Noardo, 2016), some of which explicitly refer to the themes of restoration (Fiorani \& Acierno, 2017) that allow to verify the reliability of representation (graphic and alphanumeric) by establishing relationships between concepts, allowing the description of dynamic processes flexible and open to future implementations.

\section{THE CASE STUDY}

The building was built more than five centuries ago: the particular shape of the building derives from the transformations that have taken place over the years with changes in the intended use and related stylistic trends that have formed it. Its greatest expression can be traced back to the Renaissance-Castilian style, passing through the legacy of the Muslim tradition - deriving from the strong influences of the reign of Al-Andalus (Andalusia) - both united by a type of construction that often provides for the presence of a patio. In the meantime, under the Christian regime, the building took shape and evolved from a typical house with a double patio belonging to the Italian merchant Stefano Centurione (1513) to the noble palace of the Mendoza family, which added to the building a portico system with columns in the Renaissance style (mid-16th century). In the second half of the 18th century the palace was converted into a hospital: it was enlarged with another part that took over the previous patio, with great respect

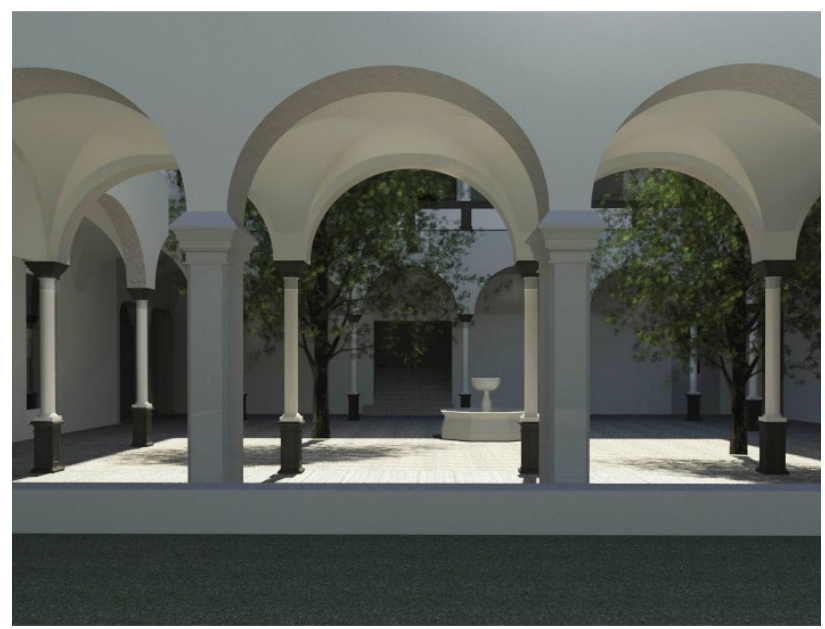

Figure 2. View of the Patio, ground floor - HBIM model

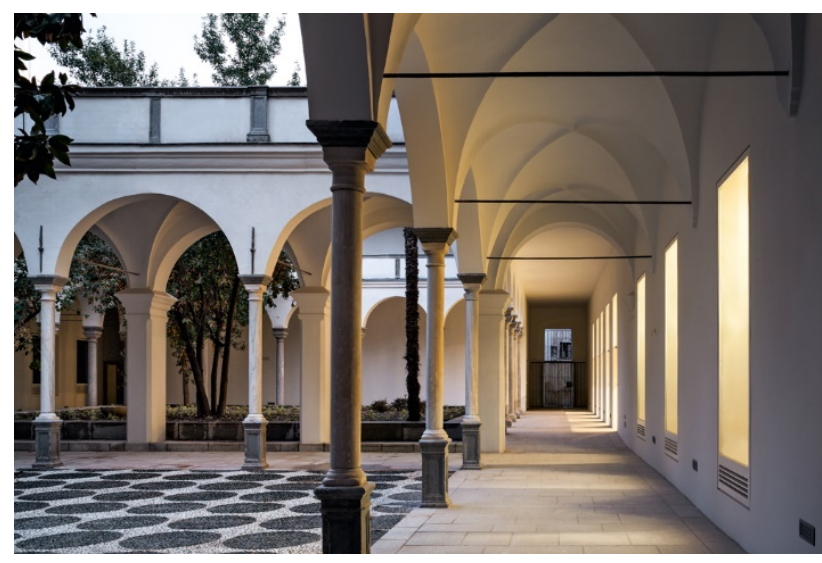

Figure 3. Picture of the Patio at the ground floor 


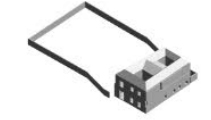

The first house had two patios: the main one and the service one

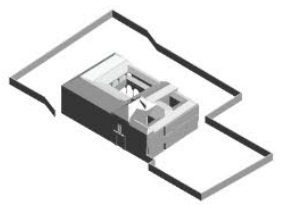

The palace of mendoza has shaped the patio as we see it today

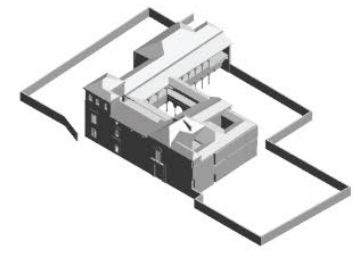

A wing is added in perfect harmony with the previous intervention

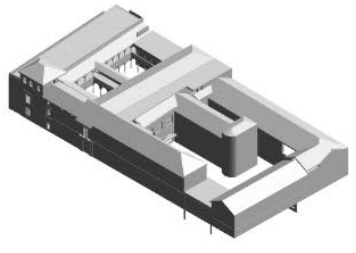

The block takes the form we see today

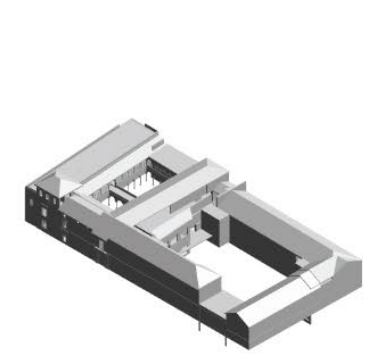

The building is acquired by the school of architecture

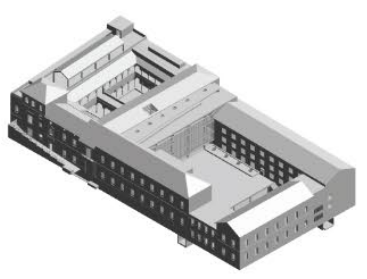

The project will take place in 2015. A new patio is set against the old one

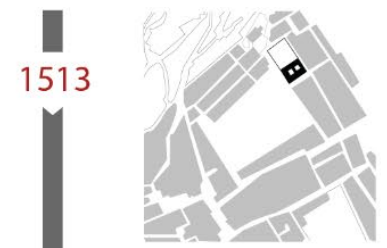

䧑
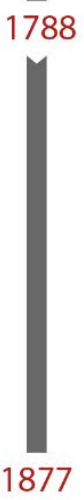

1944
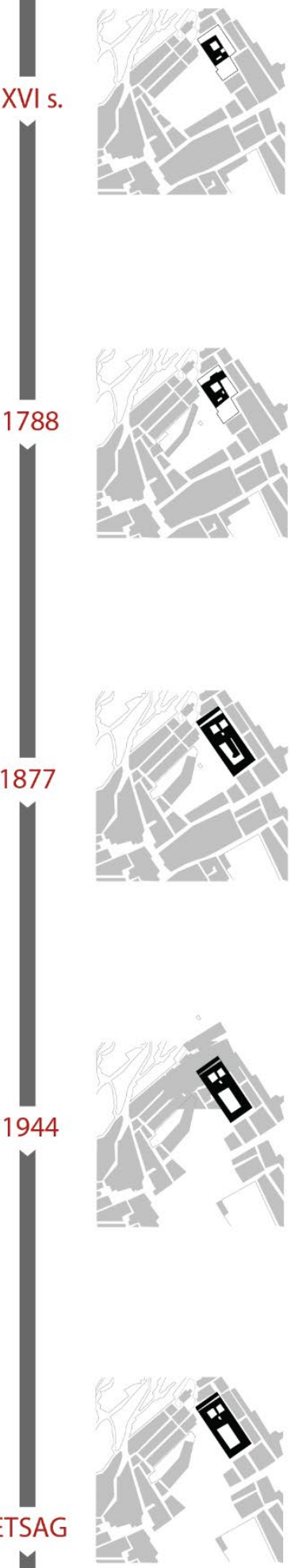

for the existing and most of its stylistic characteristics that are still perceptible. Then, a church on the north side was annexed to the complex. The building had no significant transformation until 1865 , when the building was converted into a Military Hospital (Sanchez, 2003).

In summary, there have been more than thirty interventions that have shaped the block as we see it today, also following the recent changes of the existing to adapt it to new needs: in this regard, it is important to remember project of the V.L. Cotelo. He was the winner of a competition launched by the University of Granada and the ETSAG following the acquisition in 1994 of the disused building. The project aimed to restore the building to a state of formal clarity: the elements of historical value are enhanced, and the new interventions - reduced to a minimum - do not prevail over the built but is identified only as a distribution element for the permeability of a complex in which past and present are perfectly integrated (Cotelo, 2016). Surely the patio, object of an in-depth analysis, is one of the most interesting part of the entire building which is structured through the contrast between the old and the new, represented by a new patio opposite to the historical one. The patio is divided into two levels, made up of Tuscan columns that rest on a base made of Piedra de Helvira, the same material used for the capital. The shaft is made of white marble, and the portico consists of cross vaults. The same for the Planta Principal, where the columns support lowered arches instead of the round arches on the lower floor. The 18th century Patio is characterized by rib vaults and decorative elements between the arches that simulate alfiz. Below it is a description of the methodological approach used to virtualize the geometric and informative information found during the research, with particular attention to the elements making up the patio.

\section{METHODOLOGICAL APPROACH}

The apparatus of knowledge consisting of the information collected, is not only a representation of the historical artifact in its geometric characteristics, but also a document of integrated storage, aimed at determining a localized information system. The intent to investigate an innovative methodology of knowledge through Building information Modeling followed by an upper level ontology structure to bring together all the informations about the historic building, using a digital model in which all the documental system of the archives, in a hierarchical and rational way, and that is placed as an element of easier use and greater accessibility to knowledge, as well as a more reliable and complete document for the protection and preservation of the cultural asset. At the regard, by avoiding the dispersion and redundancy of historical and technical information, it is possible to implement more conscious protection and intervention protocols.

The aim is to create semantic-aware models, which can be updated over time with the inclusion of additional data, supporting the concept of implementation of the relational database, prepared to interface with the ontologies of the CIDOC-CRM system, as illustrated below.

\subsection{Data collection}

Figure 4. Timeline of evolution-phases

The historical/archival research has been a rich support to the understanding of the building in its evolutionary and historical complexity; this is also confirmed by the "Ante-proyecto" studies, which describe the archaeological investigations and recreate the most important steps for a clear and orderly understanding of the chronological events.

The original documents of V.L. Cotelo's project are stored in

the ETSAG's Library; they constitute an important technical

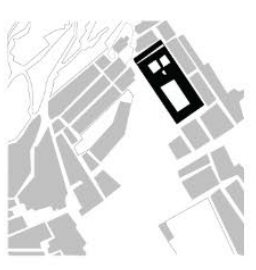




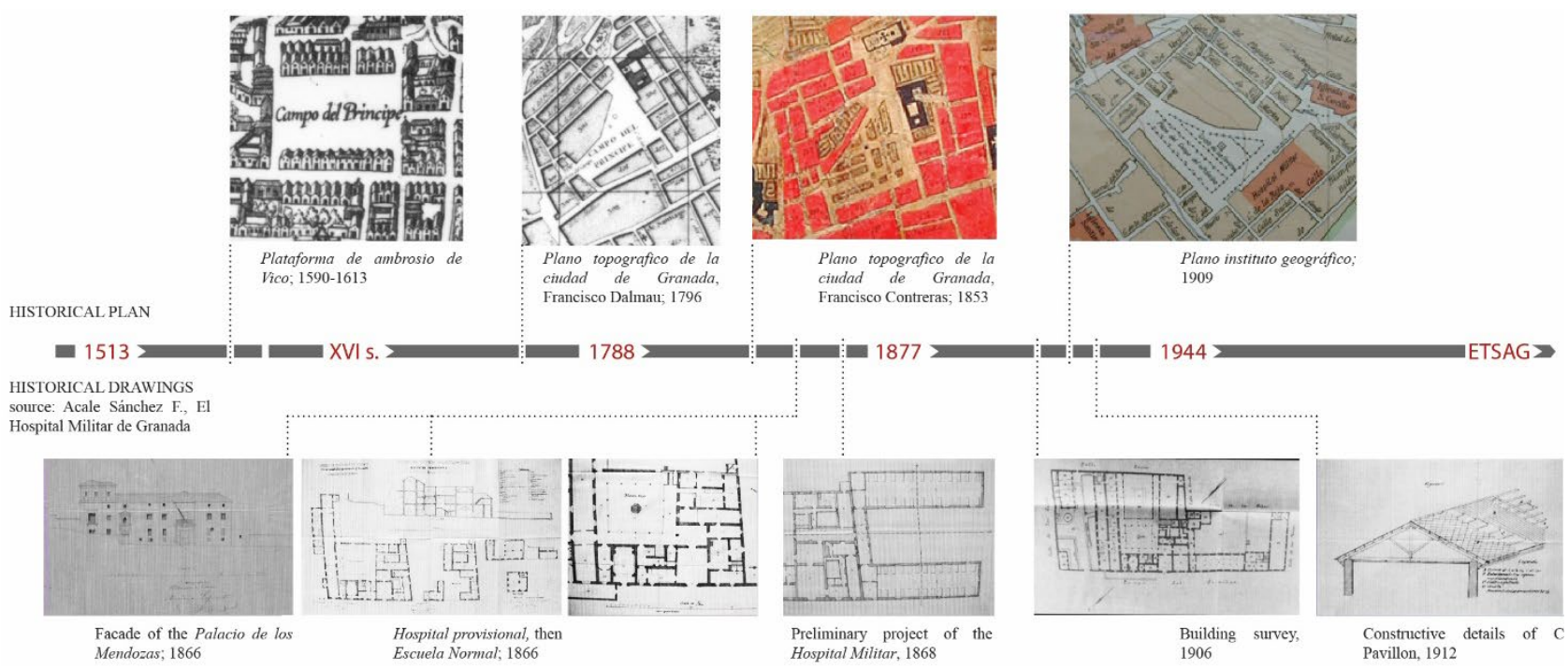

Figure 5. Timeline that includes part of the archival documentation collected during the research

and informative documentation: the respect of the naming used in the archive documents allows to maintain a rational organization of the digital model consistent with the archival collected documentation (Chiabrando, Donato, Lo Turco, \& Santagati, 2018). The most important ones for the realization of the model are:

1) Preliminary studies, which include investigations (corings, inspections, spectrometry), the description of the building divided into units and its explanatory annexes, the graphic documentation divided into thematic plans, technical drawings and stratigraphic studies;

2) The repository of the interventions, including the Plan de Obra, a detailed description of the project, including the definition of the technical elements and the description of the materials. The annex on the restoration activities provides a complete picture of the state of conservation of certain elements and the proposed procedures for intervention. There are also interesting thematic elaborations that compare New/ Demolished elements, together with some technical data sheets on the materials added to the original stratigraphy;

3) The technical drawings including the new design sheets, also available in vector format.

\subsection{HBIM Modeling}

The adoption of the BIM methodology in the field of historical construction is not only to be intended in terms of geometric precision, but it also requires a more careful consideration considering other variables of an information system (parametric components, relationships, attributes, correct definition of level of Graphic DEtail - and information -LOD- Level of Development, reinterpreted by the Italian legislation in Level of Geometry - LoG - and Level of Information, LoI).

At the same time, photographic documentation from different sources, together with technical documents about the structure of the building, contribute to the definition of the Level of Reliability of the interventions carried out, which cannot be inferred from direct survey. (Brusaporci, Maiezza, \& Tata, 2018) In order to manage these attributes, it is necessary to customize the BIM-oriented digital environment by setting specific parameters (Garagnani, 2017) and preparatory to the survey operations: from the date of construction / modification / restoration of the building components, to the archival sources consulted (later digitized and linked to the model or parts of it), to the recording of data useful for the planning of future interventions, to the organization of iconographic sources, to the most recent images and the state of preservation of the places, just to mention the main ones.

In order to make the querying of information on the BIM platform even more effective, the digital model has to be integrated with a number of specific parametric components, including:

a) Identification of the optical cones, which can be related to the entity "Rooms" and connected to the iconographic attributes found during the historical research;

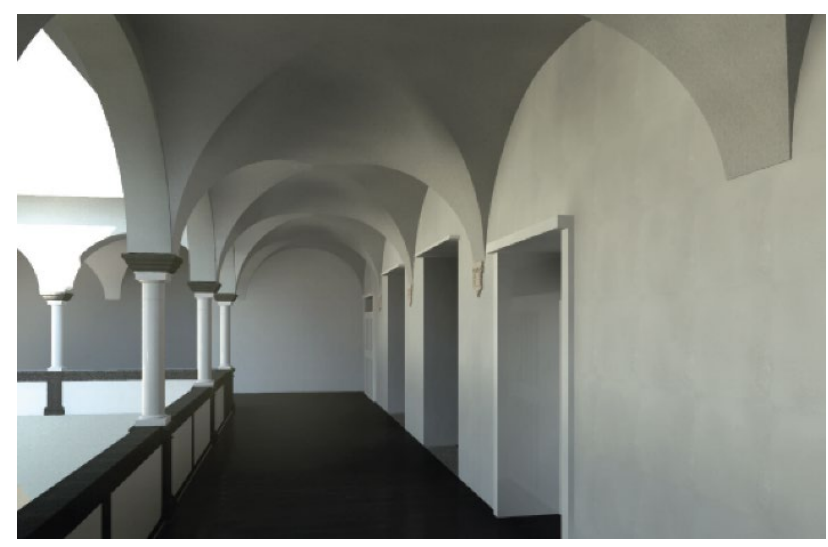

Figure 6. View of the Galeria, first floor - HBIM model

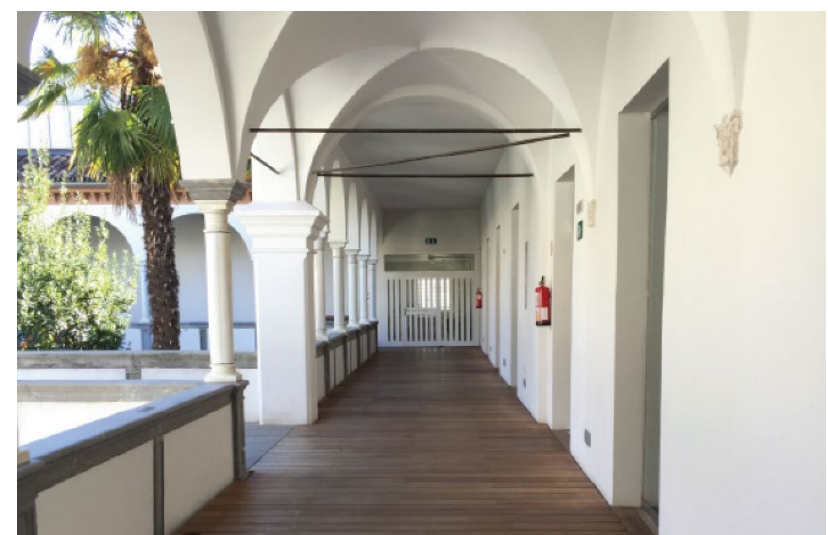

Figure 7. Photo of the Galeria, first floor 

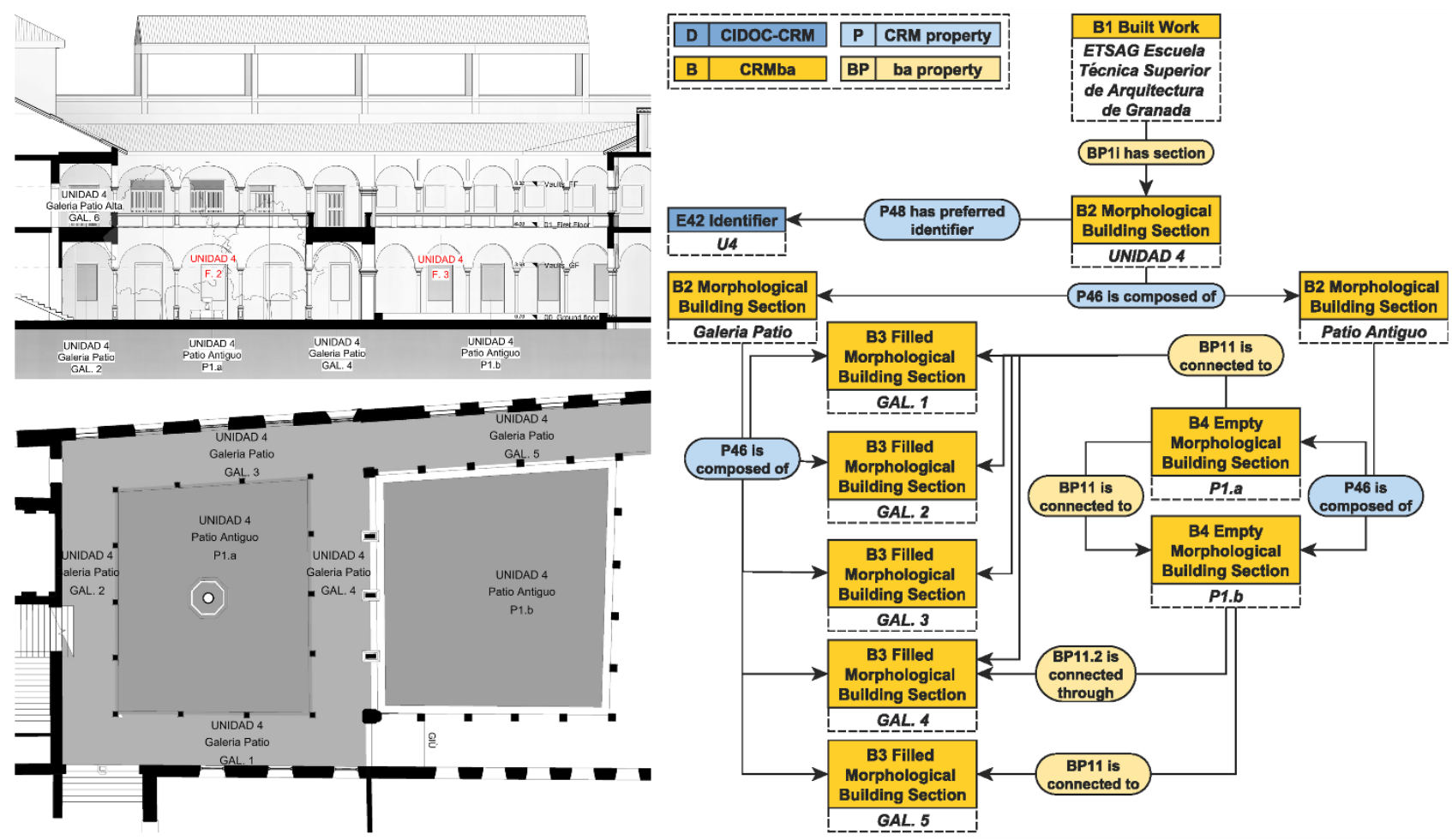

Figure 8. CRMba applied to UNIDAD 4 according with the Ground Floor Plan and Longitudinal Elevation

b) Identification of corings and inspections carried out prior to the last intervention works, to keep track of the most recent interventions, properly documented and hierarchically organized in the database associated with the parametric model. According to this, a digital model that represents the effective synthesis between the level of geometric accuracy (Garagnani \& Manferdini, 2013) and reliability of alphanumeric information contained in it. In this regard, it is worth mentioning the evaluation model proposed by a research group coordinated by Prof. Bianchini and specifically dedicated to the numerical quantification of the Level of Reliability (LoR) of the proposed reconstruction (Bianchini \& Nicastro, 2018), possibly compiled in situ and then transferred asynchronously into the parametric model, making the BIM model assume a more pronounced inclination towards the aspects of management / maintenance.

The comparison with the different stratifications would imply a wider reflection on the Level of Reliability taken from archival/bibliographic sources, from which it derives the need for a further parameter to measure the reliability of historical sources in the archaeological reconstruction of some parts of the artifact subject to heavy additions, the result of a previous experiment in which the sources were classified as: type, completeness, reliability, level of detail of the historical source, the latter further declined according to the geometric, topological, dating, material, construction systems.

In this research, the purpose of the present paper is not the essay of the critical points underlying the complex procedures of modelling elements belonging to the historicized architecture, or the measurement of the Level of Reliability of the historical sources, but rather the definition of the parametric system to receive the documentary, technical and descriptive information related to the ontological structures described below.

\subsection{Knowledge Modeling from HBIM to Conceptual Reference Modeling: a first approach}

This paragraph presents an upper-level ontology used to model semantics of the BIM "world".

The proposed solution describes the definitions of classes and properties applicable to BIM environment starting with an overview of the conceptual modelling requirements: a generic upper-level ontology based on international standard CIDOCCRM (Le Boeuf, Doerr, Emil Ore, \& Stead, 2018) has been used as a semantic layer to describe concepts and relationship commonly applied to AEC sector.

It is proposed, therefore, a reasoning on data structure, analyzing existing ontological systems of cultural heritage and proposing solutions for the organization of digital BIM models on the basis of shared criteria that could be implemented in case of H-BIM, with specific data from the cultural heritage sector. A reflection on a semantically structured model is outlined in order to understand how objects work in a BIM environment, focusing firstly in the $3 \mathrm{~d}$ modelling process then on the organization of data: it is important to understand how to catalogue and store the information in appropriate data collectors directly connected to the main $3 \mathrm{~d}$ elements of the BIM model, usually called Families (into Revit environment) maintaining a hierarchical structure among the entities, metadata and paradata. This structure, before the creation and during the creation of the model, must ensure a common and interoperable language through the semantic use of naming and encodings (ontological process).

In this sense, outlining a methodology based on international standards, it is possible to identify objects and logical relations useful for the classification and cataloguing of the building and its parts, allowing a coherent communication between heterogeneous cases that are comparable to the same formal principles, and between all the subjects and people involved: Heritage-BIM process goes from the survey of a cultural asset to the predisposition of the model to make it usable by different 


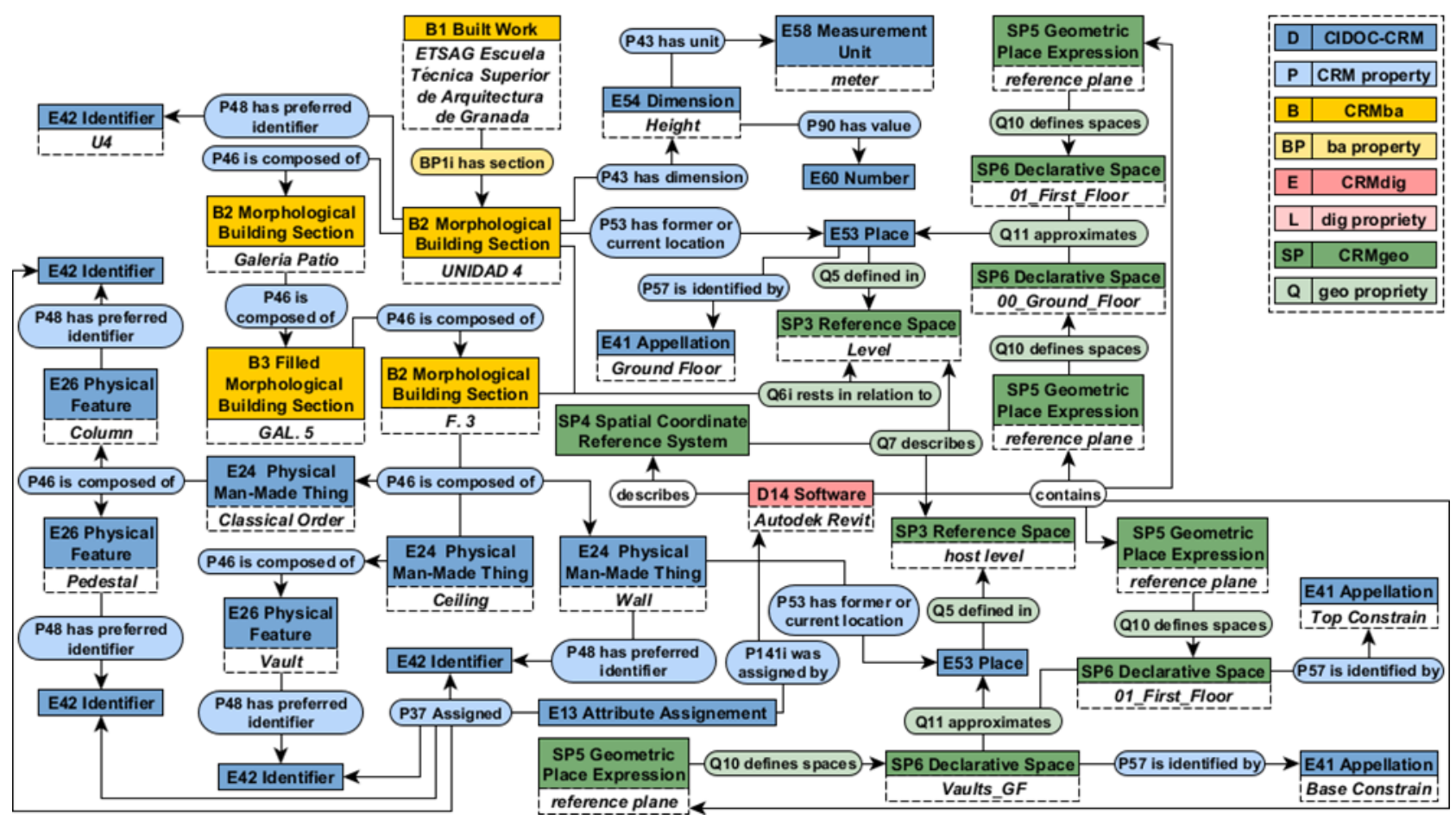

Figure 9. CRMgeo applied to UNIDAD 4 - Ground Floor and level of reference for a level-hosted wall

types of users and its informative panorama does not contain only 3D data but also $1 \mathrm{D}$ (texts) and 2D (drawings) necessaries to define the data provenance of historical considerations.

AEC sector represents an important segment of users within the CRM community even if not many methodological approaches were developed from a $3 \mathrm{~d}$ modeling point of view. Approaches related to historical buildings (Garozzo, Murabito, Santagati, Pino \& Spampinato, 2017) conservation processes (Acierno, Cursi, Simeone, \& Fiorani, 2017) and virtual reconstructions (G. Bruseker, Guillem, \& Carboni, 2015) were developed, but a direct correspondence between BIM architectural elements and CIDOC-CRM classes is still lack of investigations.

The first part of the conceptual modeling took into account the CRMba extension (Ronzino, Niccolucci, Felicetti, \& Doerr, 2016). This extension was developed to support building archaeology documentation according with the CRMarcheo extension made to support archaeological excavation process (George Bruseker, Carboni, \& Guillem, 2017). Unfortunately, as described in the introduction of the last developed version, the CRMba extension "fail in describing the completeness of information about the building and the relationship among its parts and with the whole" (Ronzino et al., 2016).

\subsubsection{Modeling spaces using CRMba}

Using the current version of the CRMba extension, it is possible to describe physical presence and absence of architectural space. The extension present, in the current version 1.4, five classes and fourteen properties that describe relationships between each of the building components among them and with the building as a whole taking into account the stratigraphic analysis theory of the standing buildings (Ronzino et al., 2016). The portion of the building investigated is the one composed by a double patio, also encoded as UNIDAD 4.

The specific case study is suitable for the testing of CRMba classes because it considers a portion of the building, B1 built work, which is composed by different kind of spaces, $B 2$ morphological building section. In this case spaces are considered as instances of man-made things that are functional units for the whole building. According with this description a CRMba section could be associate to Revit Room Class.

Revit user guide define a room as "a subdivision of space within a building model, based on elements such as walls, floors, roofs, and ceilings. These elements are defined as roombounding" (Autodesk, 2018b). The use of rooms, areas, and color schemes to plan occupancy and usage of a building is a common practice for architects, designers and structural engineers to perform basic analysis of a design.

Even if the two patios could be described as a B4 Empty Morphological Building Section surrounded by a B3 filled morphological building section that consist on a series of "Galeria" encoded with numbers, a lack of description related to Levels still remain.

Within the BIM environment a Level is a reference element and it can be described as a "finite horizontal plane that acts as a reference for level-hosted elements, such as walls, roofs, floors and ceilings" (Autodesk, 2018b). According with the case study, in which are recognizable up to 17 levels, in the UNIDAD 4 we encounter just 4 levels. Two of them, 00_Ground_Floor and 01_First_Floor could be considered as master levels because are related to the graphic architectural view style used to represent a building and its floor plans sequence. Other levels, Vaults_GF and Vaults_FF, must be considered as level of reference for level-hosted elements that in this case are walls with a sequence of empty arches that correspond to vault elements that characterizes ceilings of Galerias.

\subsubsection{Modeling Levels using CRMgeo}

CRMgeo (Hiebel, Doerr, Eide, \& Teodoridou, 2015) is a CRM extension developed to support descriptions of locations and geometry of sites. The first aim was to define a "spatiotemporal model" that could integrate geo-information available from GIS formats with cultural heritage data, creating a combination of two standards derived from both communities: the Standard for 
Geographic Information OCG/ISO and the CIDOC-CRM for representing Cultural Heritage datasets. The current version 1.2 comprise a declaration for thirteen Spatiotemporal Classes and nineteen properties that describes geophysical reasoning.

Even if the CRMgeo were developed for GIS applications purposes it is possible to find some similarities between BIM environment and E53 Places intended not only as a geometric abstraction of the space but as a spatial projection of a spatiotemporal extent of a real world phenomenon that can be observed and measured: an instance of SP2 Phenomenal Place in fact exist as long as the respective SP3 Reference Space is defined and the same structure could be identified for a Model Element that exist in relation to the level that host it.

Into BIM environment the Building Project could be described by phases, each representing a distinct time period in the life of the project. In H-BIM projects, phases are commonly used to describe evolution-phases of the building and its changes over the time (Brumana, Oreni, Raimondi, Georgopoulos, \& Bregianni, 2013)(Calcerano et al., 2017). The software is able to tracks the phase in which views or elements are created or demolished: this feature description is very similar with the $S P I$ Phenomenal Spacetime Volume definition that in CRMgeo is described as "the true extent of an instance of E18 Physical Thing during the course of its existence, from production to destruction." (Hiebel et al., 2015)

In this first conceptual mapping, the phenomenal part of the ontology was not took into account, but an explication of mapping between BIM Elements classes involved in UNIDAD 4 and CRMgeo geometrical classes is proposed.

The mapping, at this step, didn't considered the investigation about possible connection between CRMgeo and CRMdig extensions, such as the fact that we're working in a digital environment and not on reality of things.

Anyway the assumption that everything happens in a digital environment is declared by the D14 Software that in CRMdig is described as a class that "comprises software that are used to operate a system of digital objects" (Doerr, Stead, \& Theodoridou, 2015). In the conceptual model the D14 Software describe the S14 Spatial Coordinate Reference System and contains its SP3 Reference Space. A Reference space in BIM software could be intended as Level that it could be used as host-level for instances of an E24 Physical Man-Made Thing, such as, Walls, Ceilings, Architectural Elements and its Parts that are considered as E26 Physical Features because are "identifiable features that are physically attached in an integral way to particular physical objects"(Le Boeuf et al., 2018).

From an operative point of view, according with CRMgeo classes the SP4 Spatial Coordinate Reference System describes instances of SP3 Reference Space - BIM Levels - that define an instance of E53 Place where instances of B2 Building Section (see 4.3.1) have current location.

Because a generic class of B2 Morphological Building Section is used, in this mapping, both to indicate the area of interest UNIDAD 4, intended on its Ground Floor Plan, and also to indicate that area that concern the Facade 3 (F.3) with a view of the Patio (P1.b) a specification about their SP3 Reference Space it is necessary. In fact as previously specified, in a project there are two possibilities to describe Levels: for those that represent the Plan Section areas the E53 Place is approximated by two instances of SP6 Declarative Space, 00_Ground_Floor and 01_First Floor that defines the area of the section.

To describe host-levels where E24 Physical Man-Made Thing has current location, the SP6 Declarative Space instances that contain the BIM Element could change, then each instance is identified by an E41 Appellation that clarify if the SP5 Geometric Place Expression that describes the SP6 entity must be considered as a Base Constrain or a Top Constrain for the in-built architectural element.

\section{CONCLUSION AND FUTURE OUTCOMES}

The work presents a subsequent evolution of a research activity previously carried out (Lo Turco, Parisi, GomezBlanco Pontes, \& Rivas Lòpez, 2018), in which the relationship between the digital model and the information apparatus was contained within the BIM platform; this was followed by the structuring of an external database implemented through data interoperability processes (through the combined use of DBlink and Microsoft Access) that allows to operate verification activities, data enrichment and basic management operations directly done in situ with the possibility to export information into a web platform (Quattrini, Battini, \& Mammoli, 2018).

In accordance with the positions taken by colleagues who have investigated similar problems, the research aims to promote the integration of different computer methods, overcoming the limitations arising from a low semantic level of BIM systems applied to the themes of the Cultural Heritage domain (Acierno \& Fiorani, 2017).

In the later part of the research, the reasoning on the structuring of an ontology was to investigate how the classes and properties provided by the CIDOC-CRM and its extensions can be attributed to a defined portion of the building: the modelling was related to the existing and tested formalization of the Cidoc CRM Conceptual Reference Model (using its extensions CRMba, to support building archaeology documentation and CRMgeo). It is intended to be used as a global scheme for integrating spatiotemporal properties of temporal entities and persistent items. The intention is to develop an information system that includes the integration and exchange of information to validate the proposed method and then to extend the testing to the entire building. This first approach, if methodologically effective, could lay the foundations for the development of a mapping between CIDOC-CRM and IFC Standard according with latest workflows developed (Autodesk, 2018a).

\section{ACKNOWLEDGEMENTS}

The authors thank the SMLab laboratory of the University of Granada, with a specific regard to Prof. Antonio Gomez Blanco and the architect Esteban Josè Rivas Lopez for the fruitful collaboration that occurred during the research activity, together with Fernando Acale Sánchez, author of the book Hospital Militar de Granada, rich source for the knowledge of the building, and which provided some historical images of this paper. The studies previously carried out by the Drawing and Surveying Laboratory of the School of Architecture of Granada, as well as those concerning the enhancement of the Heritage, such as the drone and laser-scanner surveys, have been elements of support to the understanding of the complex, offering interesting insights that have converged in the documentation of the H-BIM model.

\section{REFERENCES}

Acierno, M., Cursi, S., Simeone, D., \& Fiorani, D. (2017). Architectural heritage knowledge modelling: An ontology-based framework for conservation process. Journal of Cultural Heritage, 24, 124-133. https://doi.org/10.1016/J.CULHER.2016.09.010

Acierno, M., \& Fiorani, D. (2017). CPM. Un'Ontologia per il Restauro. Ananke, (speciale GeoRes), 141-146. 
Autodesk. (2018a). Revit IFC manual, 1-52.

Autodesk, K. N. (2018b). Autodesk Revit 2018 Learning. Retrieved from http://help.autodesk.com/view/RVT/2018/ENU/

Bianchini, C., \& Nicastro, S. (2018). La definizione del Level of Reliability: un contributo alla trasparenza dei processi di HistoricBIM. Dn- Building Information Modeling, Data \& Semantics, 2, 45-49.

Brumana, R., Oreni, D., Raimondi, A., Georgopoulos, A., \& Bregianni, A. (2013). From survey to HBIM for documentation, dissemination and management of built heritage: The case study of St. Maria in Scaria d'Intelvi. In 2013 Digital Heritage International Congress (DigitalHeritage) (pp. 497-504). IEEE. https://doi.org/10.1109/DigitalHeritage.2013.6743789

Brusaporci, S., Maiezza, P., \& Tata, A. (2018). A framework for architectural heritage HBIM semantization and development. ISPRS - International Archives of the Photogrammetry, Remote Sensing and Spatial Information Sciences, XLII-2, 179-184 https://doi.org/10.5194/isprs-archives-XLII-2-179-2018

Bruseker, G., Carboni, N., \& Guillem, A. (2017). Cultural Heritage Data Management: The Role of Formal Ontology and CIDOC CRM. (M. L. Vincent, V. M. López-Menchero Bendicho, M. Ioannides, \& T. E. Levy, Eds.), Heritage and Archaeology in the Digital Age: Acquisition, Curation, and Dissemination of Spatial Cultural Heritage Data. Cham: Springer International Publishing. https://doi.org/10.1007/978-3-319-65370-9

Bruseker, G., Guillem, A., \& Carboni, N. (2015). Semantically Documenting Virtual Reconstruction: Building a Path to Knowledge Provenance. ISPRS Annals of Photogrammetry, Remote Sensing and Spatial Information Sciences, II5/W3(September), 33-40. https://doi.org/10.5194/isprsannals-II-5W3-33-2015

Calcerano, F., Calvano, M., Sacco, M., Ruperto, F., Gigliarelli, E., \& Cessari, L. (2017). Heritage Bim: methodological reflections and interoperability with numerical simulations. Dienne, 1 . Retrieved from http://www.dienne.org/

Chiabrando, F., Donato, V., Lo Turco, M., \& Santagati, C. (2018) Cultural Heritage Documentation, Analysis and Management Using Building Information Modelling: State of the Art and Perspectives. In E. Ottaviano, A. Pelliccio, \& V. Gattulli (Eds.), Mechatronics for Cultural Heritage and Civil Engineering (pp. 181-202). Cham: Springer International Publishing. https://doi.org/10.1007/978-3-319-68646-2_8

Cotelo, V. L. (2016). Rehabilitacion del antiguo hospital militar del campo del principe para escuela de arquitectura en Granada Espana. En Blanco, (20), 8-41.

Doerr, M., Ore, C.-E., \& Stead, S. (2007). The CIDOC Conceptual Reference Model - A New Standard for Knowledge Sharing. (pp. 51-56). https://doi.org/10.13140/2.1.1420.6400

Doerr, M., Stead, S., \& Theodoridou, M. (2015). CRMdig version 3.2.1.

Felicetti, A., Scarselli, T., Mancinelli, M. L., \& Niccolucci, F. (2013). Mapping ICCD Archaeological Data to CIDOC-CRM: the RA Schema. In V. Alexiev, V. Ivanov, \& M. Grinberg (Eds.), CRMEX 2013 Practical Experiences withCIDOC CRM and its Extensions. Valetta, Malta, September 26. Retrieved from http://ceur-ws.org/Vol-1117/paper2.pdf

Fiorani, D., \& Acierno, M. (2017). Conservation Process Model (cpm): a Twofold Scientific Research Scope in the Information Modelling for Cultural Heritage. ISPRS - International Archives of the Photogrammetry, Remote Sensing and Spatial Information Sciences, XLII-5/W1, 283-290. https://doi.org/10.5194/isprsarchives-XLII-5-W1-283-2017

Garagnani, S. (2017). Semantic Representation of Accurate Surveys for the Cultural Heritage, (July), 292-310. https://doi.org/10.4018/978-1-4666-8379-2.ch009

Garagnani, S., \& Manferdini, A. M. (2013). Parametric accuracy: building information modeling process applied to the cultural heritage preservation. ISPRS - International Archives of the Photogrammetry, Remote Sensing and Spatial Information Sciences, XL-5/W1, 87-92. https://doi.org/10.5194/isprsarchivesXL-5-W1-87-2013

Garozzo, R., Murabito, F., Santagati, C., Pino, C., \& Spampinato, C. (2017). CulTO: an ontology-based annotation tool for data curation in cultural heritage. ISPRS - International Archives of the Photogrammetry, Remote Sensing and Spatial Information Sciences, XLII-2/W5, 267-274. https://doi.org/10.5194/isprsarchives-XLII-2-W5-267-2017

Gruber, T. (2009). Ontology. In L. Ling \& M. Tamer Özsu (Eds.), Encyclopedia of Database Systems. Springer-Verlag.

Hiebel, G., Doerr, M., Eide, O., \& Teodoridou, M. (2015). CRMgeo version 1.2. Retrieved from http://www.ics.forth.gr/isl/index_main.php?l=e\&c=661\&i=

Le Boeuf, P., Doerr, M., Emil Ore, C., \& Stead, S. (2018). CIDOCCRM version 6.2.4. CIDOC Conceptual Reference Model (CRM).

Lo Turco, M., Parisi, P., Gomez-Blanco Pontes, E., \& Rivas Lòpez, A. J. (2018). Modelli HBIM per la valorizzazione e gestione del patrimonio culturale. Il caso studio della Escuela Técnica Superior de Arquitectura di Granada. In VI International Conference ReUSO (pp. 2519-2530). Messina.

Nicastro, S. (2015). L'integrazione dei sistemi di Building Information Modeling nei processi di conoscenza del Patrimonio Culturale. Premesse teoriche, criteri metodologici e introduzione del Level of Reliability. Sapienza Università di Roma Dipartimento di Storia, Disegno e Restauro dell'Architettura. Retrieved from https://core.ac.uk/download/pdf/153370911.pdf

Noardo, F. (2016). Architectural heritage ontology concepts and some practical issues. GISTAM 2016 - Proceedings of the 2nd International Conference on Geographical Information Systems Theory, Applications and Management, (January 2016). https://doi.org/10.5220/0005830901680179

Quattrini, R., Battini, C., \& Mammoli, R. (2018). HBIM to VR. Semantic awareness and data enrichment interoperbility for parametric libraries of historical architecture. https://doi.org/10.5194/isprs-archives-XLII-2-937-2018

Ronzino, P., Niccolucci, F., Felicetti, A., \& Doerr, M. (2016). CRMba version 1.4. extension of CIDOC CRM to support buildings archaeology documentation.

Sanchez, F. A. (2003). El Hospital Militar de Granada: de palacio renacentista a escuela de arquitectura. Spain: Caja San Fernando.

Santagati, C., \& Lo Turco, M. (2016). From structure from motion to historical building information modeling: populating a semanticaware library of architectural elements. Journal of Electronic Imaging, 26(1), 011007. https://doi.org/10.1117/1.JEI.26.1.011007

UNI 11337. (2017). Edilizia e opere di ingegneria civile - Gestione digitale dei processi informativi. 